\title{
Nurses' personal knowledge and their attitudes toward alcoholism issues: A study of a sample of specialized services in Brazil
}

\author{
Divane de Vargas \\ School of Nursing, University of São Paulo, São Paulo, Brazil. \\ Correspondence: Divane de Vargas, PhD, BSN. Address: School of Nursing, University of São Paulo, Enéas de Carvalho \\ Aguiar, 419, São Paulo SP-05403-000, Brazil. E-mail: vargas@usp.br
}

Received: June 13, 2013

Accepted: July 18, 2013

Online Published: October 14, 2013

DOI : 10.5430/jnep.v4n2p123

URL: http://dx.doi.org/10.5430/jnep.v4n2p123

\section{Abstract}

Background: Changes to more positive attitudes and the development of skills to enable work with alcohol- and alcoholism-related issues were associated with knowledge in the area). The aim of this report is to investigate the relationship between nurses' and nursing assistants' attitudes toward alcohol and alcoholism and their knowledge of alcohol and alcoholism issues.

Methods: The Scale of Attitudes toward alcohol, alcoholism and alcoholics and a knowledge questionnaire were completed using a convenience sample of nurses and nursing assistants $(N=75)$ working in eight clinics specializing in the treatment of alcohol and other drug problems in São Paulo City, Brazil.

Results: A positive correlation was found between the number of correct answers on the knowledge questionnaire and positive attitudes of the participants. The age of the participants $(p=.028)$, specific preparation in alcohol and other drugs during nursing education $(p=.019)$ and knowledge assessed using the Knowledge questionnaire $(p=.016)$ were significantly correlated with positive attitudes. Personal working category (nurse/nurse assistants; $p=.007$ ) significantly influenced the mean knowledge level.

Conclusion: These results indicate that nurses show more positive attitudes toward alcohol and alcoholism problems than nurse assistants and that their score on the knowledge questionnaire was on average 1.456 points higher than that of nurse assistants, suggesting a relation between higher knowledge levels and positive attitudes.

\section{Key words}

Attitudes, Alcohol, Alcoholism, Nursing, Knowledge

\section{Introduction}

Harmful alcohol use is one of the main health risks worldwide. It causes more than 60 types of illnesses and lesions and results in approximately 2.5 million deaths annually. It should also be noted that low-risk drinking impacts morbidity and mortality related to certain diseases and that, in certain population groups, alcohol consumption exceeds HIV/AIDS and tuberculosis as the main cause of death ${ }^{[1]}$. In Brazil, alcohol dependence is estimated to occur in $12 \%$ of the population; however, despite the wide distribution of users and the considerable advances made in screening and knowledge of this 
phenomenon, nursing personnel education and training in alcohol and other psychoactive substances has received little emphasis. This situation, associated with negative attitudes toward alcohol use and misuse, has influenced these professionals' lack of preparation and has impeded a more effective approach and delivery of care to persons with psychoactive substance abuse disorders. This lack of preparation and knowledge has been observed even among nurses who work in specialized alcohol and drug services in Brazil ${ }^{[2]}$.

Nursing care delivery to patients with alcohol-related problems has been documented in the literature as being difficult and is affected by the moral model of explanation of alcoholism ${ }^{[3]}$. One outcome of this situation is the negative attitude of nurses toward alcoholic patients. An association between negative attitudes and insufficient knowledge of alcohol, alcoholism and associated problems has been described by researchers ${ }^{[2,4-7]}$ as the main cause underlying the deficit in nurses' skills to identify, treat and refer these patients ${ }^{[5,8]}$. Despite this evidence, health and nursing professionals' attitudes and knowledge of alcohol and other drugs has not been properly explored in recent years ${ }^{[3,9]}$.

Recent studies on the knowledge and attitudes of nurses toward alcohol and alcoholism have indicated that nurses believe that their interventions have little influence on the drinking habits of their patients ${ }^{[10]}$, that nurses feel less confidence than other health professionals when using their knowledge and skills to treat alcoholic patients ${ }^{[1]}$ and that after training programs and courses on the area, they showed positive changes in their skills and knowledge of alcohol and associated problems ${ }^{[12]}$. With regard to attitudes, study results ${ }^{[12]}$ have suggested that nursing professionals have moral opinions and attitudes toward alcohol and associated problems despite considering alcoholism a disease ${ }^{[2]}$, judging patients' treatment motivation as recovery ${ }^{[12]}$ and disagreeing that alcoholics have character flaws ${ }^{[3,13]}$.

Studies published in the 2000s ${ }^{[3,13]}$ claim that in recent years, nurses have shown more positive attitudes toward alcohol, alcoholism and associated problems than studies from the 1980s and 1990s. In Brazil, studies have indicated that the attitudes of nurses toward alcoholism and associated problems were ambivalent ${ }^{[13,14]}$ even when considering alcoholism a disease; nurses preferred not to work with these patients, indicating the negative attitudes of nurses toward patients with alcohol abuse problems.

Many factors, such as nurses' personal characteristics, their beliefs on the causes and symptoms of alcohol abuse problems, their beliefs on their role in the care of such a patient ${ }^{[15]}$ and their own pattern of alcohol use ${ }^{[16]}$ can influence the attitudes of nurses toward the care of alcoholic patients. Various studies ${ }^{[2,7,11]}$ have attributed the main causes of the negative attitudes of nurses and difficulties in delivering care to these patient groups to the lack of knowledge of approaches and interventions for these illnesses. In contrast, a change to more positive attitudes and the development of skills to enable work with alcohol- and alcoholism-related issues were associated with knowledge offered in the area as a part of nursing education or courses and training programs ${ }^{[2,6,17]}$. However, few studies have focused on the relationship between these two variables (knowledge and attitudes). Thus, the aim of the present study was to investigate the relationship between nurses' and nursing assistants' attitudes toward alcohol and alcoholism and their knowledge of alcohol- and alcoholism-related issues.

\section{Methods}

A survey was performed at 8 specialized clinics that provide care to patients who suffer from alcohol and other drug-related problems, referred to as Psychosocial Care Centers for Alcohol and Drugs, and were active in São Paulo City, Brazil, at the time of data collection between January and June 2010. The Psychosocial Care Centers for Alcohol and Drugs are outpatient services that attend to an average of 100 patients per day. Of the 90 nursing personnel (nurses and nursing assistants) who were invited to participate in the study, 75 (83.3\%) returned the completed instruments. The ethical aspects in the development of this research were approved by the Institutional Review Board at the University where the study was implemented, and all of the subjects completed an informed consent form. 


\subsection{Sample}

The study sample comprised 75 participants, including 26 (34.6\%) nurses and $49(65.4 \%)$ nursing assistants. With regard to sociodemographic characteristics, $88 \%$ were women, $60 \%$ were single, and the mean age was 44.5 (SD 10.6) years. Many participants obtained their nursing education at private colleges $(49.3 \%)$. With regard to educational and training variables, $70.7 \%$ of the participants claimed no education in mental health, $72 \%$ claimed no specific education in alcohol and other drugs, $40 \%$ had never participated in any training program in this area, and $76 \%$ denied having any formal preparation in alcohol and other drugs during their nursing education.

Table 1. Demographics, Educational and Professional/Occupational Characteristics of Participants Enrolled in this Study Based on the Level of Education (nurse/nurse assistant)

\begin{tabular}{|c|c|c|}
\hline & $\begin{array}{l}\text { Nurse }(n=26) \\
n(\%)\end{array}$ & $\begin{array}{l}\text { Nurse assistant }(n=49) \\
n(\%)\end{array}$ \\
\hline \multicolumn{3}{|l|}{ Gender } \\
\hline Male & $4(15.4)$ & $5(10)$ \\
\hline Female & $22(84.6)$ & $44(90)$ \\
\hline \multicolumn{3}{|l|}{ Age } \\
\hline Up to 25 years & $1(04)$ & $4(8.2)$ \\
\hline Between 26 and 35 years & $6(23)$ & $6(12.8)$ \\
\hline Between 36 and 45 years & $7(27)$ & $11(22)$ \\
\hline Between 46 and 55 years & $6(23)$ & $18(37)$ \\
\hline More than 56 years & $6(23)$ & $10(20)$ \\
\hline \multicolumn{3}{|c|}{$\begin{array}{l}\text { Specific preparation in alcohol and other drugs during nursing } \\
\text { education }\end{array}$} \\
\hline Yes & $3(12)$ & $13(26.5)$ \\
\hline No & $23(88)$ & $36(73.5)$ \\
\hline \multicolumn{3}{|c|}{ Education in alcohol and drugs (courses and/or training) } \\
\hline Yes & $20(80)$ & $25(51)$ \\
\hline No & $06(20)$ & $24(49)$ \\
\hline \multicolumn{3}{|c|}{ Specialization in mental health } \\
\hline Yes & $9(35)$ & $-*$ \\
\hline No & $17(65)$ & $-*$ \\
\hline \multicolumn{3}{|l|}{ Educational institution } \\
\hline Public & $9(35)$ & $25(51)$ \\
\hline Private & $17(65)$ & $24(49)$ \\
\hline \multicolumn{3}{|c|}{ Previous professional experience at mental health services } \\
\hline Yes & $15(58)$ & $23(47)$ \\
\hline No & $11(42)$ & $26(53)$ \\
\hline
\end{tabular}

*Only Bachelors in Nursing (nurses) graduates are allowed to complete specialist courses in Brazil.

\subsection{Instruments}

The instrument used to assess attitudes was the Escala de Atitudes Frente ao Álcool ao Alcoolismo e ao Alcoolista (EAFAAA) ${ }^{[2]}$. This instrument comprises 84 items and identifies five attitude subscales that cover five factors: S1) attitudes toward alcoholic patients, work and interpersonal relations; S2) attitudes toward the etiology of alcoholism; S3) attitudes toward alcoholism as a disease; S4) attitudes toward the consequences of alcohol use/abuse and S5) attitudes toward alcoholic beverages. The EAFAAA has been used in numerous studies and has established satisfactory reliabilities of $0.84^{[13]}$ and $0.92^{[2]}$. For this study sample, the reliability index observed in the instrument estimated by Cronbach's alpha was .88. The Attitudes Scale incorporates a five-point Likert scale (ranges from 1 to 5), and participants were invited to indicate their response ( $5=$ strongly agree, $4=$ agree, $3=$ indifferent, $2=$ disagree and $1=$ strongly disagree). High scores on the EAFAAA are indicative of positive attitudes ${ }^{[2,13]}$. To assess the knowledge of respondents, a knowledge questionnaire developed and validated in 300 health professionals in Brazil ${ }^{[18]}$ was used. The Knowledge Ques- 
tionnaire ${ }^{[18]}$ comprises 4 multiple-choice questions addressing knowledge of the following topics: detection of acute intoxication, low-risk use, harmful use for health and Alcohol Dependence Syndrome. In addition, the questionnaire has a second section comprising eight true-or-false questions addressing knowledge of the following topics: tolerance, brief intervention and motivational phases of alcoholic patients. A Demographic Profile Questionnaire (DPQ) was administered together with the attitude scale and the knowledge questionnaire. The DPQ comprised three sections. Section 1 included questions regarding the participant demographics (gender, age, marital status). Section 2 included questions regarding training and education in alcohol and other drugs (courses and/or training programs, degree specializing in mental health, specific preparation in alcohol and other drugs during nursing education). Section 3 examined the subject's background and previous experience in mental health services.

\subsection{Statistical analysis}

For data analysis, the Statistical Package for Social Sciences (SPSS) software was used. Basic descriptive statistics were used to describe the responses of the participants who completed the survey. For the Knowledge questionnaire, accurate answers were totaled, and no answered question had a score of 0 . For the statistical analyses, the total knowledge questionnaire was considered to be a new variable that ranged from 0 to 12. For the Attitude scale, the variable was each participant's mean score, i.e., the sum of scores on the Attitude scale divided by the number of questions answered. Because the average score on the scale is 3 , higher scores are interpreted as signs of positive attitudes ${ }^{[2]}$. To verify the correlation between participants' attitudes and knowledge, Pearson's correlation test was used. Independent t-tests were performed to determine whether educational level (i.e., nurse or nursing assistant) influenced the relation between attitude and knowledge scores and to verify whether other interest variables (gender, age, marital status, attending courses and/or training in alcohol and other drugs, degree specializing in mental health, specific preparation in alcohol and other drugs during nursing education, previous professional experience in mental health services and knowledge questionnaire score) influenced the participants' attitudes. The same statistical test was used to verify whether these same variables influenced the knowledge score. The criterion for statistical significance was set at $p<.05$.

\section{Results}

A moderate correlation ${ }^{[19]}(r=.38)$ was observed between the study participants' attitudes toward alcohol and alcoholism-related issues and knowledge as assessed using the questionnaire. A t-test for independent samples (nurses and nursing assistants) indicated no influence of educational level on the relation between attitudes and knowledge. When independent t-tests were used to analyze the other variables' influence on the participants' attitudes, the results showed no significant influence of the independent variables gender $(p=.395)$, professional category $(p=.539)$, graduation institution $(p=.746)$, background experience at mental health services $(p=.523)$, specialist degree in mental health $(p=$ $.444)$ or education in alcohol and drugs, such as courses and/or training programs after nursing education, $(p=.522)$ on participants' attitudes toward alcohol and alcoholism-related issues. In contrast, a lower age $(p=.028)$, specific preparation in alcohol and other drugs received during nursing education $(p=.019)$ and a high score on the knowledge questionnaire $(p=.016)$ were significantly associated with more positive attitudes. When the influence of the same independent variables on the mean knowledge score was analyzed, only the professional category $(p=.007)$ influenced that variable significantly. Nurses' scores on the knowledge questionnaire were 1.456 points higher than the nursing assistants' scores.

The mean score on the attitude subscale was $3.32(s=0.46)$, indicating that participants present predominantly positive attitudes toward issues relating to alcoholism and alcoholics ${ }^{[2]}$. The highest mean score among the five EAFAAA attitude subgroups of $3.67(s=0.79)$ was observed in subgroup 1 , which measures attitudes toward working and interpersonal relations with alcoholic patients. These results indicate that participants with more accurate answers on the Knowledge questionnaire also had a higher mean score on the Attitude scale (see Table 2). Based on the attitude subgroups, this relationship was more evident in subgroups 1,2 and 5 (see Table 2). 
On average, male participants provided more correct answers on the Knowledge questionnaire (mean 6.4) than female participants (mean 5.7). However, attitudes appeared balanced between genders except for subgroup 5 (attitudes toward alcoholic beverages), in which male participants showed a higher mean score than females (see Table 3). The nurses' mean scores on the Knowledge questionnaire and Attitude scale were higher than nurse assistants' scores for subgroups 1 and 5, which address attitudes toward work and interpersonal relationships with these types of patients and the view of the professionals toward alcoholic beverages, respectively. The highest mean scores in the Knowledge questionnaire were observed in younger professionals ( $\leq 25$ years), and the same group also showed the highest scores on the Attitude scale both in general and within all subgroups except for subgroup 4 (see Table 3 ).

Table 2. Comparison between the Number of Correct Answers on the Knowledge Questionnaire and the Mean Score of the Attitude Scale and Each of the Five EAFAAA Subgroups.

\begin{tabular}{lllllll}
\hline $\begin{array}{l}\text { Number of correct answers in } \\
\text { the Knowledge questionnaire }\end{array}$ & $\begin{array}{l}\text { Mean general score } \\
\text { on the Attitude scale }\end{array}$ & $\begin{array}{l}\text { Mean score } \\
\text { S1* }\end{array}$ & $\begin{array}{l}\text { Mean score } \\
\text { S2* }\end{array}$ & $\begin{array}{l}\text { Mean score } \\
\text { S3* }\end{array}$ & $\begin{array}{l}\text { Mean score } \\
\text { S4* }\end{array}$ & $\begin{array}{l}\text { Mean score } \\
\text { S5* }\end{array}$ \\
\hline $\mathbf{2}$ & 2.9 & 3.4 & 2.4 & 2.7 & 1.9 & 3.3 \\
$\mathbf{3}$ & 3.2 & 3.3 & 3.2 & 3.1 & 3 & 3.2 \\
$\mathbf{4}$ & 3.1 & 3.6 & 2.7 & 2.8 & 1.9 & 3.1 \\
$\mathbf{5}$ & 3.1 & 3.2 & 3 & 2.8 & 2.8 & 3.2 \\
$\mathbf{6}$ & 3.4 & 3.7 & 3.1 & 2.9 & 2.6 & 3.6 \\
$\mathbf{7}$ & 3.5 & 4 & 3.4 & 3.1 & 2.7 & 3.5 \\
$\mathbf{8}$ & 3.7 & 4.4 & 3.7 & 3.1 & 2.4 & 3 \\
$\mathbf{9}$ & 3.9 & 4.3 & 3.4 & 2.7 & 2 & 3.7 \\
\hline
\end{tabular}

* Attitudes Subgroup 1, 2, 3, 4, 5

Table 3. Comparison between the Demographics of the Respondents and their Mean Scores on the Knowledge and Attitude Questionnaires.

\begin{tabular}{|c|c|c|c|c|c|c|c|}
\hline \multirow[b]{2}{*}{ Variable } & \multicolumn{4}{|c|}{ Demographic characteristics } & \multirow[b]{2}{*}{$\begin{array}{l}\text { Mean } \\
\text { score } \\
\text { S3* }\end{array}$} & \multirow[b]{2}{*}{$\begin{array}{l}\text { Mean } \\
\text { score } \\
\text { S4* }\end{array}$} & \multirow[b]{2}{*}{$\begin{array}{l}\text { Mean } \\
\text { score } \\
\text { S5* }\end{array}$} \\
\hline & $\begin{array}{l}\text { Mean number of correct } \\
\text { answers on knowledge } \\
\text { questionnaire }\end{array}$ & $\begin{array}{l}\text { General mean } \\
\text { score on attitude } \\
\text { scale }\end{array}$ & $\begin{array}{l}\text { Mean } \\
\text { score } \\
\text { S1* }\end{array}$ & $\begin{array}{l}\text { Mean } \\
\text { score } \\
\text { S2* }\end{array}$ & & & \\
\hline \multicolumn{8}{|l|}{ Gender } \\
\hline Male & 6.4 & 3.2 & 3.5 & 3.0 & 2.9 & 2.6 & 3.9 \\
\hline Female & 5.7 & 3.3 & 3.5 & 3.1 & 3.0 & 2.7 & 3.2 \\
\hline \multicolumn{8}{|l|}{ Age } \\
\hline Up to 25 years & 5.8 & 3.7 & 4.1 & 3.5 & 3.5 & 2.4 & 3.8 \\
\hline Between 26 and 35 years & 4.2 & 3.3 & 3.4 & 3.0 & 3.1 & 2.9 & 3.4 \\
\hline Between 36 and 45 years & 5.5 & 3.4 & 3.8 & 3.2 & 2.8 & 2.8 & 3.3 \\
\hline Between 46 and 55 years & 5.0 & 3.1 & 3.2 & 3.1 & 3.0 & 2.8 & 3.2 \\
\hline More than 56 years & 5.1 & 3.2 & 3.5 & 2.9 & 2.7 & 2.2 & 3.6 \\
\hline \multicolumn{8}{|l|}{ Professional Category } \\
\hline Nurse assistants & 5.4 & 3.0 & 3.5 & 3.1 & 3.0 & 2.8 & 3.2 \\
\hline Nurse & 6.8 & 3.8 & 3.6 & 3.1 & 3.0 & 3.0 & 3.7 \\
\hline
\end{tabular}

* Attitudes Subgroup 1, 2, 3, 4, 5

When comparing educational variables (preparation in alcohol and other drugs during nursing education, courses and/or training programs in alcohol and drugs after nursing education and specialist degree in mental health) and background experience in mental health services, the participants with some education in alcohol and other drugs (courses and/or training programs after nursing education) showed better performance on the Knowledge questionnaire and a higher general score on the Attitude scale. 
The results of this study also indicated that participants with a specialist degree in mental health performed better on the Knowledge questionnaire, but no significant differences were observed in the mean scores on the Attitude scale between this group and the participants who did not receive specialized instruction in this area, except for subgroup 1, which measures attitudes toward working and interpersonal relationships with alcoholic patients. The same result was observed when comparing the background experience of these two groups in mental health services. Participants with previous experience in mental health services performed better on the Knowledge questionnaire but obtained lower average scores on the Attitude scale than participants who did not have this experience (see Table 4).

Table 4. Comparison between Respondents' Education and Previous Experience at Mental Health Services and Their Mean Scores on the Knowledge Questionnaire and Attitude Scale.

\begin{tabular}{|c|c|c|c|c|c|c|c|}
\hline \multicolumn{8}{|c|}{ Socio-educational characteristics } \\
\hline & $\begin{array}{l}\text { Mean correct answers } \\
\text { on the Knowledge } \\
\text { questionnaire }\end{array}$ & $\begin{array}{l}\text { Mean general } \\
\text { score on the } \\
\text { Attitude scale }\end{array}$ & $\begin{array}{l}\text { Mean } \\
\text { score } \\
\text { S1* }\end{array}$ & $\begin{array}{l}\text { Mean } \\
\text { score } \\
\text { S2 } *\end{array}$ & $\begin{array}{l}\text { Mean } \\
\text { score } \\
\text { S3* }\end{array}$ & $\begin{array}{l}\text { Mean } \\
\text { score } \\
\text { S4* }\end{array}$ & $\begin{array}{l}\text { Mean } \\
\text { score } \\
\text { S5* }\end{array}$ \\
\hline \multicolumn{8}{|c|}{$\begin{array}{l}\text { Education in alcohol and drugs } \\
\text { (courses and/or training) }\end{array}$} \\
\hline Yes & 6.7 & 3.7 & 3.6 & 3.2 & 3.1 & 2.7 & 3.6 \\
\hline No & 5.6 & 3.3 & 3.7 & 3.1 & 2.9 & 2.5 & 3.3 \\
\hline \multicolumn{8}{|c|}{$\begin{array}{l}\text { Specific preparation in alcohol and } \\
\text { other drugs during nursing } \\
\text { education }\end{array}$} \\
\hline Yes & 6.5 & 3.8 & 3.6 & 3.5 & 3.0 & 2.7 & 3.5 \\
\hline No & 5.0 & 3.0 & 3.1 & 3.0 & 2.9 & 2.7 & 3.0 \\
\hline \multicolumn{8}{|c|}{ Specialization in mental health } \\
\hline Yes & 6.0 & 3.2 & 3.9 & 2.7 & 2.7 & 2.2 & 3.1 \\
\hline No & 5.0 & 3.3 & 3.3 & 3.2 & 2.9 & 2.6 & 3.4 \\
\hline \multicolumn{8}{|c|}{ Educational institution } \\
\hline Public & 5.7 & 3.3 & 3.6 & 3.5 & 3.0 & 2.6 & 3.3 \\
\hline Private & 5.0 & 3.3 & 3.6 & 3.1 & 3.0 & 2.8 & 3.5 \\
\hline \multicolumn{8}{|c|}{$\begin{array}{l}\text { Previous professional experience at } \\
\text { mental health services }\end{array}$} \\
\hline Yes & 5.8 & 3.2 & 3.5 & 3.1 & 2.9 & 2.6 & 3.3 \\
\hline No & 5.4 & 3.4 & 3.7 & 3.2 & 3.0 & 2.6 & 3.5 \\
\hline
\end{tabular}

* Attitudes Subgroup 1, 2, 3, 4, 5

In a comparison of participants who had received nursing education at public colleges or universities with those who had studied at private institutions, the participants who had studied at public colleges had higher mean scores on the Knowledge questionnaire, whereas no significant difference was observed between these groups (public versus private) in Attitude scores (see Table 4).

\section{Discussion}

The results of this study suggest that a positive relationship exists between the attitudes of nursing personnel toward alcohol and alcoholism-related problems and their knowledge. These findings are consistent with previous studies ${ }^{[6,10,16]}$ indicating that knowledge of alcohol and its associated problems influences attitudes and, consequently, the delivery of care to persons with alcoholism-related problems. The results also demonstrated that participants with some training in alcohol and drug abuse after their nursing education and/or who received some type of preparation for working with these health problems during their nursing education showed higher mean scores on the Knowledge questionnaire and Attitudes scale than participants who did not have this experience. Thus, educational interventions significantly affect the 
knowledge and attitudes of health professionals ${ }^{[6,7,16]}$. However, only the preparation received during nursing education showed a significant association with more positive attitudes, which suggests that the preparation delivered gradually during initial nursing education is more effective in enhancing attitudes than the preparation offered in courses and training programs completed after concluding formal professional education.

Despite higher mean scores on the Knowledge questionnaire, the participants who had already worked in psychiatric and mental health services or who had a specialist degree in Psychiatric and Mental Health Nursing showed essentially the same scores as participants who did not have these experiences. The reason underlying this finding is unclear, and additional research is required in this area; however, these data suggest that the participants who had already worked with psychiatric and mental health patients tended to perceive alcoholic patients more negatively. Although changes have been observed in recent years, the moral model remains and permeates many nurses' perceptions and attitudes toward alcoholism and alcoholic patients ${ }^{[3]}$. In contrast, contact with alcohol and alcoholism-related problems at mental health service clinics and a specialization in Psychiatric and Mental Health Nursing did increase knowledge of alcohol and other drugs without significantly influencing the attitudes toward these types of patients. These results also suggest that knowledge regarding psychoactive substances is not capable of influencing professionals' attitudes, even in the context of Psychiatric Mental Health Nursing specialist courses in Brazil. This fact creates a context for future studies to investigate this situation because it is already known that a lack of attention to alcohol and other drugs exists in undergraduate Brazilian nursing curricula ${ }^{[4,20]}$.

Previous studies have demonstrated that in Brazil, the average time devoted to drug and alcohol education in public colleges and universities is between four and eight hours in psychiatric and mental health subjects ${ }^{[4]}$ compared to two to three hours in private institutions ${ }^{[20]}$. Evidence exists that the number of hours dedicated to alcohol and alcoholism-related problems in medical ${ }^{[12]}$ and nursing education ${ }^{[20]}$ is significantly associated with more positive attitudes of the eventual professionals. This research indicates that alumni from public institutions who received more hours of education and more content covering the use of alcohol and other drugs during nursing education ${ }^{[4,20]}$ obtained higher scores on the Knowledge questionnaire than students from private colleges and universities. The same relationship was not observed in attitudes because the mean scores observed on the Attitude scale were nearly identical between the two groups, which may suggest that the method and amount of content offered did not influence the participants' attitudes significantly.

As expected, the nurses obtained higher mean scores than the nursing assistants on the Knowledge questionnaire and Attitude scale. In addition, the professional category was the only variable that showed a significant influence on knowledge scores, which indicated that, on average, nurses scored higher than the nursing assistants on the questionnaire and reinforced the finding that a positive correlation exists between higher knowledge levels and positive attitudes.

Consistent with previous studies ${ }^{[3,15,20]}$ this study suggests that the personal characteristics of the professionals influence their attitudes toward alcohol and alcoholism-related problems. Younger professionals were more likely to show positive attitudes and high scores on the Knowledge questionnaire, whereas older participants were more prone to negative and stereotyped views of alcoholics ${ }^{[20]}$. A recent study ${ }^{[15]}$ has shown that the motivation to work with people with alcoholrelated problems is greater among younger nurses. An explanation for this result may be that younger professionals have received some preparation in this healthcare area compared with older professionals who graduated earlier in Brazil. Although the number of hours in alcohol and drugs content in curricula is inadequate, this education, in combination with the increased availability of information and widely disseminated knowledge in communication media regarding the physiological, behavioral and cognitive causes of these conditions ${ }^{[15]}$, has resulted in greater acceptance of alcohol-related problems in people in general and, consequently, in nursing personnel.

With regard to gender, female participants typically showed higher mean scores on the Attitude scale than males in all subgroups except subgroup 5, which measures attitudes toward alcoholic beverages. These data are consistent with a previous Brazilian study ${ }^{[20]}$ indicating that females are more likely to show positive attitudes toward issues related to 
alcoholism and alcoholics. Previous studies ${ }^{[15-16]}$ have also shown that nurses' own personal patterns of alcohol consumption influence their attitudes toward alcoholic beverages. Thus, knowledge of the higher prevalence of alcohol consumption among men may underlie the fact that men showed more positive attitudes toward alcoholic beverages than women.

\section{Study limitations}

This research offers a perspective on nurses' personal attitudes and knowledge at services specialized in the delivery of care to people with alcohol and other drug-related problems in São Paulo City, Brazil. Many of the results are consistent with previous reports, and although it could be expected that nurses would perform better on the Knowledge questionnaire than nurse assistants, this study suggests a positive correlation between better attitudes toward alcohol and alcoholismassociated problems and knowledge about the theme, contributing to understanding this phenomenon. Nevertheless, these results should be considered in the context of various limitations. Although the data were collected in the largest Brazilian city, the sample is limited to a sole geographical region that was located in southeastern Brazil and is relatively small. Hence, the generalizability of these results to other health professionals at services specializing in alcohol and drugs in other areas is limited. Indeed, the mixed group demographics (nurses and nursing assistants) represent the largest limitation of this study, and future studies should enroll participants with the same educational level. It is unclear whether the answers of those who chose not to participate (16.7\%) would have contributed differently. Another limitation is the fact that some variables associated with knowledge and attitudes, such as the pattern of alcohol use in the respondents ${ }^{[16]}$ and ethnic origin ${ }^{[17]}$, were not investigated. The instrument used to measure knowledge did not cover all dimensions of the research problem and may not reflect the entirety of the participants' knowledge of the problem. This study is therefore of interest, in a broad sense, to the area of addiction nursing because it provides data on subjects who have been little studied and supports the provision of knowledge in this area of nursing, which remains incipient around the world. Lastly, this study also contributes evidence on the relationship between attitudes toward alcohol and associated problems and the level of knowledge in these areas and indicates that the provision of knowledge in these areas during nursing education is necessary to enable more adequate nursing care for those who suffer from alcohol and alcohol-associated problems.

\section{Conclusions}

Our data suggest that a positive relationship exists between the knowledge of nursing professionals and their attitudes toward alcohol, alcoholism and alcoholics. In general, the participants demonstrated positive attitudes toward alcohol and alcohol-associated problems. Personal characteristics influenced attitudes toward alcohol and alcohol-associated problems. Educational experience tended to influence knowledge more than attitude, and our results also suggest that the formal preparation received during nursing education is more likely to positively influence both the knowledge and attitudes of the eventual professionals than training offered after this formal period of education. We suggest that further research should be completed using samples with other demographics and from other health services by enrolling professionals with a more homogenous level of education and with a view to clarifying the questions raised here.

\section{References}

[1] World Health Organization. Global Status report on alcohol and health. Geneva, Switzerland: WHO; 2011.

[2] Vargas, D. Reduced version of the scale of attitudes toward alcohol, alcoholism, and alcoholics: primary results. Revista da Escola de Enfermagem da USP. 2011; 45(4): 918-925. http://dx.doi.org/10.1590/S0080-62342011000400018

[3] Howard, O.M., \& Chung, S.S. Nurse's attitudes toward misusers a Surveys. Substance use and misuse. 2000; $35(3): 347-365$. PMid:10714451http://dx.doi.org/10.3109/10826080009147701

[4] Rassool, G.H., \& Luis, M.A.V. Tackling drung and alcohol misuse in Brazil: priorities and challenges for nurses. International Nursing Review. 2004; 51: 201-207. PMid:15530160http://dx.doi.org/10.1111/j.1466-7657.2004.00248.x 
[5] Kelleher, S., \& Cotter, P. A descriptive study on emergency department doctors' and nurses' knowledge and attitudes concerning substance use and substance users. International Emergency Nursing. 2008; 17: 3-14. PMid:19135010http://dx.doi.org/10.1016/j.ienj.2008.08.003

[6] Arthur, D. The effects of the problem-based alcohol early-intervention education package on the knowledge and attitudes of students of nursing. Journal of Nursing Education. 2001; 40(2): 63-72. PMid:11214850

[7] Tran, D.T., Stone, A.M., Fernandez, R.S., Griffiths, R.D. \& Johnson, M. Changes in general nurses' knowledge of alcohol and substance use and misuse after education. Perspectives in Psychiatric Care. 2009; 45(2): 128-139. PMid:19366423

[8] Sillanaukee, P., Kaariainen J., Sillanaukee, P., Puotanen, P., \& Sappa, K. Substance use related outpatient consultations in specialised health care: an underestimated entity Alcoholism. Clinical and Experimental Research. 2002; 9: 1359-1364.

[9] Soares, J., Vargas, D., \& Oliveira, M.A.F. Health Professionals' attitudes and knowledge about alcohol, alcoholism and alcoholics: a survey of the scientific publications in the last 50 years. SMAD Revista eletrônica saúde mental, álcool e drogas. 2011; 7(1): 45-52.

[10] Johansson, K., Bendtsen, P., \& Akerlind, I. Early intervention for problem drinkers: readiness to participate among general practitioners and nurses in Swedish primary health care. Alcohol \& Alcoholism. 2002; 37(1): 38-42. http://dx.doi.org/10.1093/alcalc/37.1.38

[11] Indig, D., Copeland, J., Conigrave, K.M., \& Rotenko, I. Attitudes and beliefs of emergency department staff regarding alcohol-related presentations. 2009; 17: 23-30. PMid:19135012http://dx.doi.org/10.1016/j.ienj.2008.08.002

[12] Aalto, M., Pekuri, P., \& Seppä, K. Primary health care nurses' and physicians' attitudes, knowledge and beliefs regarding brief intervention for heavy drinkers. . 2011; 96(2): 305-311. http://dx.doi.org/10.1046/j.1360-0443.2001.96230514.x

[13] Vargas, D., \& Luis M.A.V. Development and validation of a scale of attitudes toward alcohol, alcoholism and alcoholics. Revista Latino-Americana de Enfermagem. 2008;16(5): 895-902. PMid:19061028http://dx.doi.org/10.1590/S0104-11692008000500016

[14] Pillon, S.C., \& Laranjeira, R.R. Formal education and nurses' attitudes toward alcohol and alcoholism in a Brazilian sample. São Paulo Medical Journal. 2005; 123(4): 175-180. PMid:16389415http://dx.doi.org/10.1590/S1516-31802005000400004

[15] Crothers, C.E., \& Dorrian, J. Determinants of nurses' attitudes toward the care of patients with alcohol problems. International Scholarly Research Network Nursing. 2011. Article ID 821514, doi:10.5402/2011/821514. http://dx.doi.org/10.5402/2011/821514

[16] Vadlamudi, R.S., Adams, S., Hogan, B., Wu, T. \& Wahid, Z. Nurses' attitudes, beliefs and confidence levels regarding care for those who abuse alcohol: impact of educational intervention. Nurse Education in Practice. 2008; 8: 290-298. PMid:18042433http://dx.doi.org/10.1016/j.nepr.2007.10.003

[17] Rassool, G.H. \& Rawaf, S. Predictors of educational outcomes of undergraduate nursing students in alcohol and drug education. Nurse Education Today. 2008; 28: 691-701. PMid:18166248http://dx.doi.org/10.1016/j.nedt.2007.11.005

[18] Silva, CJ. Impacto de um curso em diagnóstico e tratamento do uso nocivo e dependência do álcool sobre a atitude e conhecimento de profissionais da rede de atenção primária à saúde (Doctoral Thesis, Escola Paulista de Medicina, São Paulo, Brasil, 2005.

[19] Cohen, J. A power primer. Psychological Bulletin. 1992; 112: 155-159. PMid:19565683 http://dx.doi.org/10.1037/0033-2909.112.1.155

[20] Vargas, D. Nursing students' attitudes toward alcohol, alcoholism and alcoholics: a study of a brazilian sample. Journal of Nursing Education and Practice. 2012; 2(1): 1-7. http://dx.doi.org/10.5430/jnep.v2n1p1 